\title{
Biblioteca Ayacucho: un sueño de religación continental
}

\author{
Marcela Croce ${ }^{1}$ \\ Facultad de Filosofía y Letras/INDEAL, Universidad de Buenos Aires, Argentina
}

Resumen: El artículo reconstruye la organización de la Biblioteca Ayacucho, concebida como un canon latinoamericano postulado en la segunda mitad del siglo XX, sobre la base de los antecedentes de Andrés Bello y Pedro Henríquez Ureña. El texto se divide en dos partes: una dedicada a la propuesta general de la colección y a las vicisitudes de su realización (investigada sobre todo a partir de la correspondencia de Ángel Rama con los intelectuales convocados); otra dedicada a evaluar la relación entre los textos publicados y las imágenes seleccionadas para la portada de cada volumen. El objetivo es demostrar la forma en que la editorial se implementó como una alternativa a la "Utopía de América" en su dimensión de política cultural. En ambas partes, se hace hincapié en la presencia del Cono Sur en la colección, lo que demuestra la importancia de una empresa en la que Brasil es efectivamente integrado en América Latina.

Palabras clave: Canon latinoamericano; Edición latinoamericana; Correspondencia intelectual.

Título: Biblioteca Ayacucho: um sonho de religação continental

Resumo: O artigo reconstrói a organização da Biblioteca Ayacucho, concebida como um cânon latino-americano postulado na segunda metade do século $X X$, com base nos antecedentes de Andrés Bello e Pedro Henríquez Ureña. O texto divide-se em duas partes: uma dedicada à proposta geral da coleção e às vicissitudes de sua concretização (pesquisada sobretudo pela correspondência de Ángel Rama com os intelectuais convocados); outro dedicado a avaliar a relação entre os textos publicados e as imagens selecionadas para a capa de cada volume. A vontade é demonstrar o modo como a editora foi implantada como alternativa à "Utopía de América" em sua dimensão de política cultural. Em ambas as partes, há uma ênfase na presença do Cone Sul na coleção, o que demonstra a importância de uma empresa onde o Brasil é efetivamente integrado na América Latina.

Palavras-chave: Cânon latino-americano; Edição latino-americana; Correspondência intelectual.

Title: Biblioteca Ayacucho: A Dream of Continental Religation

Abstract: The article reconstructs the organization of the Biblioteca Ayacucho, conceived as a Latin American canon postulated in the second half of the 20th century on the basis of the background of Andrés Bello and Pedro Henríquez Ureña. The text is divided into two parts: the first one dedicated to the general proposal of the collection and to the vicissitudes of its concretion (researched above all through the correspondence of Ángel Rama with the contributors between the intellectuals); the last one dedicated to evaluate the relationship between published texts and selected images for the cover of each volume.

\footnotetext{
${ }^{1}$ Doctora en Letras. Profesora Regular de Literatura Latinoamericana - Departamento de Letras - Facultad de Filosofía y Letras/INDEAL, Universidad de Buenos Aires-UBA, Argentina. Orcid: https://orcid.org/0000-00016625-1281.
}

E-mail: marcelacroce@gmail.com 
The will is to demonstrate the way in which the project was deployed as an alternative to the "Utopia of America" in its cultural policy dimension. In both partes, there are emphasis in the the presence of South Cone into the collection, what demonstrates the importance of an enterprise where Brazil is effectively integrated into Latin America.

Keywords: Latin American Canon; Latin American Edition; Intellectual Correspondence.

\section{Origen y antecedentes}

La Biblioteca Ayacucho constituye el mayor repositorio de textos clásicos de América Latina producido durante el siglo XX. El impulso provisto por Ángel Rama -designado Director Editorial-- derivó en una serie que, para el momento de la muerte del crítico, superaba el centenar de ejemplares editados. El propósito era poner a disposición de un público amplio -- aunque mayoritariamente compuesto de universitarios y especialistas, los más preparados para enfrentarse a los prólogos que presentaban cada volumen-- un conjunto de obras y autores a partir de los cuales se constituye la idea misma de América Latina. La multivocidad del término justifica la confluencia de poesía indígena precolombina, crónicas de Indias, proclamas independentistas, especulaciones políticas, novelas, relatos y esas formas más híbridas en las que confluyen la sociología y la biografía -los casos del Facundo o Los sertones--2 o bien la antropología y la autobiografía (el ejemplo obligado es Casa grande y senzala). En la misma condición latinoamericana abarcativa se escuda la publicación de las cartas del Barón de Humboldt --alguien que no solamente pensó en América Latina y la auscultó con las herramientas científicas de la época, sino que podría identificarse como disparador de la literatura latinoamericana moderna--- ${ }^{3}$ y la inclusión del haitiano Jacques Roumain, por no abundar en la aparición de un filipino entre los diez primeros títulos, cuya razón se revela mediante la indagación de la correspondencia de Rama en torno a Ayacucho.

La colección $-y$ en este punto es preferible utilizar indistintamente los términos "colección" y "biblioteca", aunque el primero acarrea un principio de orden al cual el crecimiento desregulado y aleatorio de la biblioteca se resiste-- fue creada en virtud del decreto 407 (10 de septiembre de 1974) del presidente venezolano Carlos Andrés Pérez para conmemorar el sesquicentenario de la Batalla de Ayacucho. En ella, las fuerzas americanas comandadas por el mariscal Antonio José de Sucre consolidaron la independencia del continente frente a las tropas realistas del general José de la Serna. El enfrentamiento se produjo en la Pampa de Quinua, en el departamento peruano de Ayacucho, el 9 de

\footnotetext{
${ }^{2}$ Los títulos se citan tal como figuran en los respectivos volúmenes de la BA, en traducción al español.

${ }^{3} \mathrm{Me}$ amparo al menos en tres ejemplos para sostener tal afirmación que admite otros respaldos adicionales: es Humboldt quien postula que el Planalto es una antigua llanura marítima, hipótesis que recupera Euclides da Cunha al inicio de Os sertões; también es un personaje de la novela La fragata de las máscaras de Tomás de Mattos a fines del siglo XX y el primer protagonista del drama Humboldt y Bonpland taxidermistas de Ibsen Martínez orillando el siglo XXI.
} 
diciembre de 1824.

Venezuela se había visto favorecida por la escalada del precio del crudo dispuesta en 1973 por la Organización de Países Exportadores de Petróleo (OPEP), lo que liberaba recursos para emplear en diversas empresas. Una de ellas fue la cultural, representada por la Biblioteca. Otra, simultánea, tomaba sesgadamente el nombre de Sucre -Gran Mariscal de Ayacucho-- para disponer becas de formación de militares venezolanos en academias norteamericanas y de estudiantes nacionales en todo el mundo, especialmente en Europa.

Ángel Rama se encontraba en Caracas en esos años -donde lo sorprendió el golpe de Estado autoproclamado por el presidente de su país, Juan María Bordaberry- como profesor de la Universidad Central de Venezuela. La experiencia en el trazado de colecciones como la Enciclopedia Uruguaya y el dominio de los aspectos editoriales que había ejercitado desde el sello Arca, creado por él en Montevideo y desde el cual había difundido a Gabriel García Márquez antes de la consagración de Cien años de soledad, lo habilitaba como el especialista más idóneo para ocuparse de la dirección literaria de una colección dominada por intelectuales locales. El titular de la Biblioteca Ayacucho era José Ramón Medina, poeta a la par de Fiscal General de la Nación, lo que evidencia el carácter oficial del emprendimiento. Lo secundaban en la Comisión Editorial Ramón J. Velázquez, Oswaldo Trejo, Miguel Otero Silva, Ramón Escobar Salom y Simón Alberto Consalvi; más tarde se agregaron Pascual Sambrano Urdaneta, Pascual Venegas Filardo y Pedro Francisco Lizardo.

Aunque como todo emprendimiento novedoso el de Biblioteca Ayacucho no fue ajeno a entusiasmos iniciales, Rama no tardó en decepcionarse del entorno caraqueño: los funcionarios venezolanos ejercían un excesivo contralor económico que amenazaba la libertad de la empresa cultural, al tiempo que los intelectuales latinoamericanos convocados para diseñar un canon continental mostraban más interés en difundir a los clásicos de sus respectivos países que en practicar una mirada supranacional. Los avatares de la iniciativa constan en el Diario que Rama escribió entre 1974 y 1983 (RAMA, 2008), como así también en la correspondencia que mantuvo con colegas y amigos para ir perfilando los sucesivos volúmenes.

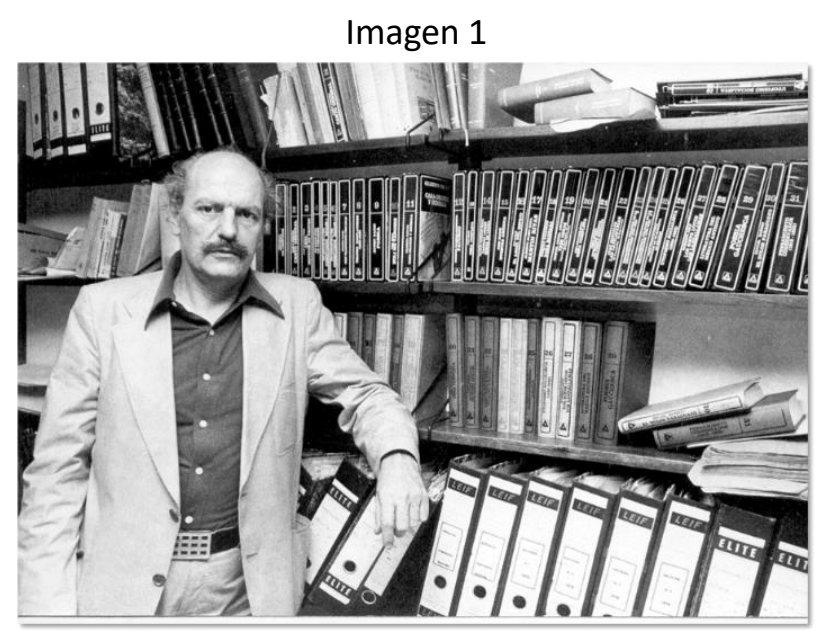




\section{Modelos tácitos y explícitos}

El modelo más remoto corresponde a la Biblioteca Americana editada en Londres en 1823 por Andrés Bello y Juan García del Río, aunque el responsable colectivo era "Una sociedad de americanos". Se trataba de un compilado de artículos diversos, que alternaban la poesía con las técnicas de cultivo, la música con la geografía, la anatomía con los minerales, sobre el bastidor que proveía la Enciclopedia francesa patrocinada por Jean D'Alembert y Denis Diderot, a cuya impronta hay que atribuir la inclusión inicial de un grabado neoclásico de ostensible estetización indígena. El propósito era dar a conocer América ante los americanos, sobre todo después de los siglos de opresión colonial que España les había deparado a los territorios al oeste del Atlántico. Así lo revela el "Prospecto" de presentación de la Biblioteca Americana, en el que se trazan las directrices generales y las divisiones internas de esta serie de publicaciones que comprenden tres "cuadernos": el primero dedicado a Humanidades y Artes Liberales; el segundo a Ciencias Matemáticas y Físicas con sus aplicaciones; y el tercero a Ideología, Moral e Historia. El propósito de la obra es el de la utilidad, como evidencia la preocupación por los aspectos prácticos de los temas abordados (si bien el punto de partida es la "Alocución a la poesía", del propio Bello).

La siguiente iniciativa de Bello fue el Repertorio Americano, lanzado también en Londres, en cuatro tomos publicados entre 1826 y 1827 . Al objetivo de difundir lo propio y de poner a disposición documentos que se conservan apenas "en las arcas de los curiosos" se suma el de "ser útiles a la América" (BELLO, 1973). Con el mismo grabado inicial, la apertura de los volúmenes son las "Silvas americanas" con las que Bello procura poetizar la naturaleza local.

Las dos grandes ediciones de Bello tuvieron repercusión en el siglo siguiente. El Repertorio Americano, con su afán de obra periódica, dio nombre a la revista editada por Joaquín García Monge en Costa Rica entre 1919 y 1958, en la cual reunió a colaboradores de toda Hispanoamérica; por su parte, Biblioteca Americana fue la designación escogida por el dominicano Pedro Henríquez Ureña para la colección de clásicos que le encargó Daniel Cosío Villegas en 1945, a fin de integrar al catálogo de Fondo de Cultura Económica.

La Biblioteca Americana fue un gran proyecto de escasa concreción. En 1946 falleció Henríquez Ureña, dejando preparado un listado de títulos que dividían en cinco secciones la producción más representativa de las letras continentales:

- Literatura indígena

- Cronistas de Indias

- Literatura colonial

- Literatura moderna 
- Viajeros. Este último segmento incorporaba a aquellos extranjeros que hubieran tomado a América como objeto de estudio o de relato, práctica muy frecuente especialmente en los siglos XVIII y XIX (HENRÍQUEZ UREÑA, 1946).

Aunque integraba a Brasil, la colección mantenía el topónimo "Hispanoamérica" y excluía obras de autores vivos, por estimar que solamente el paso de cierto lapso podía establecer si un texto se convertía o no en un clásico. El folleto de presentación de la Biblioteca Americana, lanzado por la editorial en 1946, fue redactado por Camila Henríquez Ureña y recogía, además de los criterios de su hermano, la serie de quinientos títulos que debían formar el conjunto. El primero era el Popol Vuh que, como advertía don Pedro en Las corrientes literarias en la América hispánica (1949), corresponde a una "mano mestiza" (HENRÍQUEZ UREÑA, 1978) aunque se presenta como recopilación de leyendas mayas.

La Biblioteca Ayacucho recuperó algunos de los títulos de su antecesora inmediata pero especialmente se centró en los autores, prefiriendo a veces otras obras que las que componían la selección de Henríquez Ureña. Asimismo, el inicio de estas empresas fue diferente. Si, para Bello, el opresor frente al cual se definía América era España, en 1974 crisis de la OPEP inminente y Segunda Guerra Mundial mediante-- la mayor amenaza la representaba Estados Unidos. También para Henríquez Ureña el imperio del Norte era una preocupación superlativa: su padre Francisco Henríquez y Carvajal había sido expulsado de la presidencia de la República Dominicana por los marines, y él mismo, como integrante del Ateneo de México, había sido uno de los impulsores de la edición regiomontana (e inconsulta) del Ariel en México. El libro de José Enrique Rodó, lanzado en 1900 como reacción casi inmediata a la guerra hispano-norteamericana de 1898, constituía un Evangelio de la juventud que también informaría la Reforma Universitaria ocurrida en Córdoba en 1918 y extendida desde allí por el continente.

Precisamente el Ariel formará parte de la trilogía inaugural de la Biblioteca Ayacucho, al lado de la Doctrina del Libertador -en la cual se recupera el interés en la figura de Bolívar ya desarrollado por Rufino Blanco Fombona durante su exilio en Madrid, donde fundó la Editorial América (1915-1933) en la cual rescató la obra bolivariana (SEGNINI, 2000)--4 y de ese recorrido poético por la geografía americana que es el Canto General de Pablo Neruda. La Biblioteca Ayacucho constituye el canon literario que todavía continúa operando en la enseñanza de la literatura latinoamericana, sobre todo en lo que corresponde a los siglos XIX y XX.

\footnotetext{
${ }^{4}$ Blanco Fombona sería un modelo para Rama también en el plano de las reflexiones personales, ya que Camino de imperfección. Diario de mi vida (1906-1913) (1933) es una referencia admitida por el crítico en su Diario 1974-1983.
} 


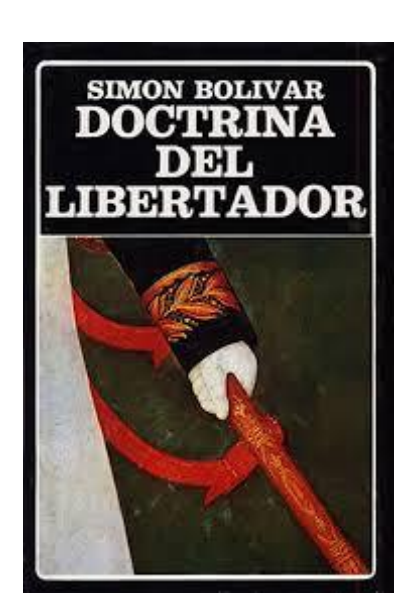

Imagen 2

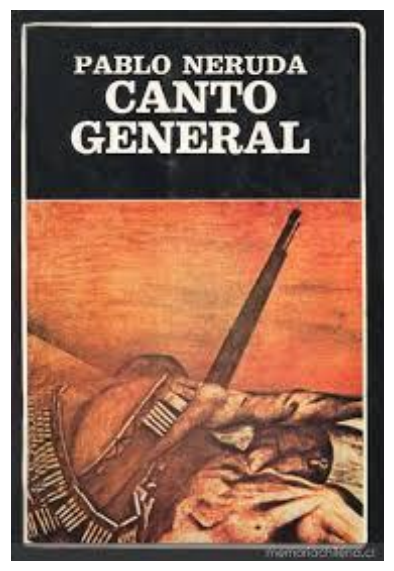

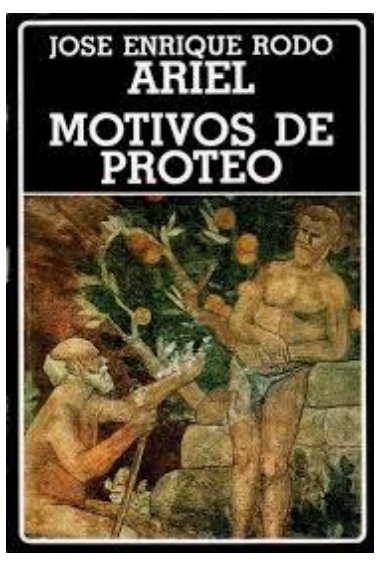

Desde 1983 --en inesperada coincidencia con la muerte de Ángel Rama en un accidente aéreo en el mes de noviembre, en las inmediaciones de Madrid-- la UNESCO emprendió una iniciativa editorial que lleva el nombre de Colección Archivos y que, de manera muy irregular, continúa publicándose. Su propósito era menos canónico que el de la Biblioteca Americana y menos histórico-político que el de la Biblioteca Ayacucho; la originalidad consistió en una iniciativa de corte filológico que se evidencia en la disposición general de los volúmenes. Mientras la Biblioteca Americana reservaba un prólogo y un conjunto de notas a cada edición y la Biblioteca Ayacucho sumaba a esta estructura una cronología de exhaustividad variable que situaba la obra en el contexto latinoamericano y mundial, la Colección Archivos propuso un modelo mucho más complejo.

El rigor filológico comenzaba exigiendo que el texto estuviera disponible en sus originales, o al menos en la primera edición. A eso añadía una introducción, una imprescindible nota filológica, el establecimiento del texto, la cronología, la historia de la obra, lecturas críticas de la misma encargadas especialmente para el volumen, un dossier ilustrativo -que podía contener cartas, dibujos, reproducción de manuscritos y críticas contemporáneas a la edición princeps-- y una bibliografía final. Como en buena parte de los volúmenes de Ayacucho, la obra de la portada correspondía habitualmente a un artista plástico de la misma nacionalidad del autor del texto (o incluso del mismo autor, como ocurre en los casos de Lúcio Cardoso y Oliverio Girondo) y el conjunto de la colección revestía una uniformidad que Ayacucho solamente modificó cuando en los años 90 sobrevino una segunda tanda editorial.

\section{La Biblioteca Ayacucho en marcha}

El verdadero motor de la Biblioteca Ayacucho fue Rama, aunque solamente haya figurado como Director Literario. A él correspondió la iniciativa de una reunión general de intelectuales latinoamericanos para proponer los títulos que formarían la colección, de la cual se ausentaron los invitados brasileños, a quienes el gobierno dictatorial les impidió salir 
del país (RAMA, 2008).

La logística del conjunto también corrió por su cuenta y, si bien disponía de recursos como para encargar prólogos --con remuneraciones variables según el colaborador convocado--, la redacción de las cartas en las que convidaba a diversos especialistas para organizar las secciones fijas de los tomos queda bajo su exclusiva responsabilidad. ${ }^{5}$

En ese conjunto de misivas, Rama despliega dotes de sociabilidad literaria poco frecuentes en la época: conoce a los autores, tiene relaciones cordiales con la mayoría de ellos --en el caso de Darcy Ribeiro, incluso entabla un vínculo epistolar paralelo con la esposa del antropólogo, Berta, quien lo ayudará a conseguir materiales gráficos (COELHO; ROCCA, 2015)--, está al tanto de sus actividades (así, por ejemplo, sospecha que Sergio Ramírez tal vez deba abandonar la preparación del volumen sobre Salarrué por haber sido nombrado secretario de la Universidad de Costa Rica; RAMA, 9 de agosto de 1976) y no vacila en pedir informaciones adicionales a alguno de ellos cuando no confía plenamente en quien se ocupa de un texto; el ejemplo es la carta a Antonio Cornejo Polar en la cual solicita bibliografía extra sobre el Lunarejo (RAMA, 2 de octubre de 1978).

La correspondencia, invariablemente mecanografiada y con la firma manuscrita de Rama, llevaba el membrete de la Biblioteca Ayacucho, localizada en el edificio del Banco Exterior -Oficina 322. Avenida Urdaneta esquina Urapal. Caracas, Venezuela. A fines del año siguiente a la creación de Ayacucho, en diciembre de 1975, se agrega al papel esquela la dirección de cable BIAYACUCHO y el Apartado postal 2177. Un membrete más completo incorpora el renglón "Ángel Rama - Director Literario".

La fórmula general de presentación de la Biblioteca, dirigida a los primeros convocados, consta en la carta enviada por Rama a Leopoldo Zea el 21 de agosto de 1975, donde a la firma de Rama se suma la de Medina como presidente de la Comisión:

Para honrar cumplidamente la Batalla de Ayacucho, que hace ciento cincuenta años liberó a los pueblos de esta región el mundo de la dominación colonial, permitiéndoles iniciar su desenvolvimiento libre e independiente, el gobierno de Venezuela, por decreto del Poder Ejecutivo, ha dispuesto la creación de una Biblioteca Latinoamericana, denominada Ayacucho, destinada a reunir en esmeradas ediciones, anotadas y prologadas por escritores e investigadores del continente, lo mejor que en materias de literaturas, historia, filosofía, pensamiento político y sociológico ha aportado a lo largo de sus varios siglos de existencia, Nuestra América.

Dicho proyecto, que reanuda los que parcialmente realizaron grandes figuras intelectuales como Rufino Blanco Fombona y Pedro Henríquez Ureña, entre otro, procurará fijar en una biblioteca cerrada, el conjunto de aportaciones culturales originales que ha proporcionado al mundo América Latina desde el legado indígena hasta las creaciones contemporáneas, mediante ediciones cuidadas que permitan a las nuevas generaciones conocer la contribución de las generaciones pasadas y difundir los grandes valores del pensamiento y la creación literaria de que se

\footnotetext{
${ }^{5}$ Estos materiales fueron consultados gracias a la generosidad y la disposición de la depositaria del archivo, Amparo Rama, quien lo conserva en Montevideo.
} 
enorgullece el continente.

Con el fin de proceder al plan de dicha biblioteca, haciendo la selección de los autores y las obras que obligadamente han de ser incluidos en ella, ha dispuesto la Comisión Editora de la Biblioteca Ayacucho la reunión de un conjunto de expertos en diversos aspectos de la cultura latinoamericana, la cual tendrá lugar en la ciudad de Caracas del 3 al 7 de noviembre próximo (RAMA, 21 de agosto de 1975).

La revisión de la correspondencia aporta datos que no se encuentran en otras fuentes. La carta a Sergio Ramírez del 3 de diciembre de 1975 señala el interés por la obra histórica de Antonio José de Irisarri antes que por la narrativa, lo que lleva a seleccionar Historia crítica del asesinato del Gran Mariscal de Ayacucho, texto muy adecuado para iniciar la colección pero que finalmente nunca se publicó. Además de invitar a Ramírez a hacerse cargo de Salarrué, Rama le solicita la edición del Popol-Vuh lanzada por EDUCA (RAMA, 3 de diciembre de 1975), que contiene la versión de la Biblioteca Americana aparecida en México en 1947 con traducción de Adrián Recinos. La misma es reclamada en la misiva de 1977 en que consta la preparación de la antología Literaturas prehispánicas de México, a cargo de Miguel León-Portilla (RAMA, 18 de mayo de 1977).

El envío a Zea a fines de 1975 deja constancia de que fue el filósofo mexicano quien propuso incluir al filipino José Rizal en la colección (RAMA, 16 de diciembre de 1975), del que se editaría en el n 10 la "novela tagala" Noli me tangere, con prólogo del propio Zea. Tal incorporación ratifica que Ayacucho promovió una definición latinoamericana establecida a partir de la guerra hispano-norteamericana de 1898. En la misma misiva, Rama consulta al filósofo en torno a un prologuista para Evolución del pueblo mexicano de Justo Sierra, sugiriendo que podría ser el mismo Zea, si estuviera interesado, y agregando que la tarea está remunerada con mil dólares (Íbid.). Sin embargo, el volumen 21 dedicado a dicha obra fue preparado por Abelardo Villegas y estampó en su portada uno de los murales de Diego Rivera del Palacio Nacional para subrayar la condición mexicana del volumen. Tampoco hay interés de Zea en la organización del número sobre Antonio Caso; en este punto Rama parece plegarse a la idea -también aplicada habitualmente en la selección de las tapas de la Biblioteca-- de que los autores de un país deben ser abordados por un connacional. Mucho más tarde, en el no 160 --cuando Rama ya había fallecido--, se edita La Filosofía como Compromiso de Liberación del propio Zea, con prólogo y cronología a cargo de Liliana Weinberg de Magis (argentina instalada en México) y Mario Magallón.

La esquela a Ribeiro del 12 de marzo de 1976 provee detalles sobre el modo de organizar las cronologías, uno de los rasgos distintivos de la BA junto con los prólogos de especialistas:

Cada volumen lleva una cronología en tres columnas: autor y obra; su país y América Latina, pol.econ.cultural; el mundo circundante e influyente en ese mismo período. Hay variantes (algunos comienzan con el nacimiento del autor, otros con su primera obra, o sus estudios) y desde luego la recopilación sobre A. Latina y Mundo externo, toma en cuenta en cada caso la dedicación del autor (si es novelista, atendemos literatura; si es un sociólogo, las ciencias humanas, and so on) (RAMA, 12 de marzo de 1976). 
En la misiva a Mario Vargas Llosa de marzo de 1976, además de solicitarle la edición de Los ríos profundos y algunos cuentos selectos de José María Arguedas, Rama se permite una ironía en torno a la radicación europea del autor de La ciudad y los perros:

he pensado difamarte como miembro del 'jet-set': eso tiene un efecto fulminante sobre los estudiantes de las Universidades. Sólo me detiene la necesidad de fijar previamente las condiciones del match, con compromiso escrito de tu parte de que no recurrirás al pugilismo (RAMA, 22 de marzo de 1976).

La frase hace referencia al incidente en el que Vargas Llosa le propinó un puñetazo a Gabriel García Márquez en el Palacio de Bellas Artes de México el 12 de febrero de 1976, un mes antes de la carta, alegando que respondía a lo que el colombiano le había hecho a su esposa Patricia en Barcelona. El matrimonio Vargas Llosa estaba en medio de una separación y nunca se aclaró cuál era el hecho que el peruano creía estar vengando y que determinó una pelea irreconciliable entre ambos escritores del boom.

A Vargas Llosa se le ofrecen mil dólares por la preparación del volumen sobre Arguedas; a José Pedro Díaz, en cambio, apenas seiscientos por la organización del tomo dedicado a Felisberto Hernández, pese a las dimensiones del mismo y a que deberá tomar bajo su cargo también la cronología del narrador uruguayo: "un tomazo de 400 páginas (tamaño de la Biblioteca Americana del Fondo)" (RAMA, 31 de mayo de 1976), lo que representa una prueba adicional de que la creación de Henríquez Ureña operaba como modelo también en los aspectos formales de Ayacucho. En la carta siguiente a Díaz, el 11 de junio de 1976, formula una aclaración que será fuente de distanciamiento de Rama con el colega montevideano, quien se había entusiasmado con la edición de Felisberto aunque en verdad se le arrebataba lo más codiciado de la misma, el prólogo. Rama se lo había encargado a Julio Cortázar, a quien empleaba a modo de salvoconducto para que los directivos de Ayacucho admitieran publicar la narrativa del narrador uruguayo a quien desconocían.

\section{Los argentinos}

El 6 de julio de 1976 Rama le escribe a Tulio Halperin Donghi (RAMA, 6 de julio de 1976). En ese mensaje, además de encomendarle un volumen de cuatrocientas páginas para el cual solicita un buen título (que finalmente será Proyecto y construcción de una nación. Argentina 1846-1880 - BA 68), le informa que los Romero, "father and son", están preparando El pensamiento de la independencia (cuya designación definitiva es Pensamiento político de la emancipación, 1790-1825, publicado en dos tomos - BA 23 y 24) y también revela que, en el mismo orden historiográfico, procura la colaboración de José Carlos 
Chiaramonte (quien será responsable de la edición completa de Pensamiento de la Ilustración. Economía y sociedad iberoamericanas en el siglo XVIII - BA 51). Como se ve, los historiadores argentinos tienen a su cargo volúmenes de corte general, los que se completan en el marco de la colección con Pensamiento conservador (1815-1898) - BA 31 y Pensamiento positivista latinoamericano (2 tomos - BA 71 y 72 ).

Para presentar el conjunto ante Halperin, a quien le rogará en otra esquela que no se exceda con la antología y que modere la extensión del prólogo (luego devenido libro independiente, y ya llamado por Rama "libro prologal"; RAMA, 24 de noviembre de 1977), aunque admite que "es un trabajo de primera y por eso se hace perdonar la extensión" (RAMA, 24 de agosto de 1978) Rama afirma que los volúmenes aparecidos hasta entonces son, "si no serios, por lo menos bellísimos, cosa que en este mundo invadido por la basura no deja de ser un descanso" (RAMA, 6 de julio de 1976). Ese señalamiento subraya el modo en que las reproducciones artísticas en las portadas de los libros contribuyen directamente a la condición estética de la BA.

El volumen Teatro rioplatense (1886-1930) - BA 8 reúne a dos argentinos en labor mancomunada. David Viñas redacta el prólogo y Jorge Lafforgue toma a su cargo la selección de obras y la cronología. La articulación es provechosa, ya que la intervención de Lafforgue le confiere al conjunto una variedad que tal vez se hubiera visto más restringida en una antología hecha por Viñas -quien había descubierto a Armando Discépolo para la crítica unos años antes al realizar un extenso prólogo para un grupo de obras escogidas del dramaturgo (VIÑAS, 1969) y aprobaba la intervención del uruguayo Florencio Sánchez en el planteo de cuestiones políticas (lo sindica como un anarquista de comienzos del siglo XX; VIÑAS, 1974), pero tal vez hubiera excluido manifestaciones dramáticamente menos desarrolladas. Por su parte, el texto de Viñas reviste la contundencia propia de su estilo, además de insistir en los tópicos de su sistema crítico; así, a las trimembraciones de los títulos que distinguen su retórica se añaden las "constantes con variaciones" y las metáforas fluviales en la apertura que representa "un circuito con sus momentos, densificaciones, variables y rasgos generales" (VIÑAS, 1978).

\section{Alternativas políticas}

La carta a Halperin Donghi del 6 de julio de 1976 es remitida a Berkeley, donde el historiador tiene un cargo docente, y hace referencia a la situación argentina y al probable impedimento en la comunicación derivado de ella: "esta carta no sé si te llegará nunca; puedes haber partido ya para Argentina y es sabido que de allí nadie sabe si retornará" (RAMA, 6 de julio de 1976). La situación de América del Sur abruma en esa referencia en la cual queda aludida la censura a que era sometida la correspondencia por parte de los regímenes militares, de los cuales el argentino se va perfilando en ese período inicial como uno de los más sangrientos. 
En un mensaje a Idea Vilariño aborda tanto el volumen que ella prepara sobre William Henry Hudson -castellanizado como Guillermo Enrique Hudson para la BA, que también convertiría a Alexander von Humboldt en Alejandro de Humboldt-- como el prólogo que envió para la edición de poesía de Julio Herrera y Reissig --"realmente bueno" (RAMA, 14 de abril de 1978), cuyos ademanes corteses al distribuir la información le recuerdan a Rama "las maneras concisas y algo irónicas" (íbid.) que utilizaba Henríquez Ureña. Allí el crítico inscribe su impresión personal sobre el caso uruguayo: "Lo único que me sigue ligando al país es la existencia de algunos amigos: lo demás como si se hubiera disuelto de un modo tan drástico que a mí mismo me desconcierta y da miedo" (íbid.).

Si el exilio (tanto interior como interamericano $y$, con frecuencia, europeo) será un tema recurrente a la vez en la correspondencia y en el Diario, ligado a los avatares dictatoriales en que se sumergen los países latinoamericanos en la década de 1970, hay otros aspectos políticos que conciernen en forma directa al armado de la colección. La marca ominosa de la prohibición y de los intereses locales, que visiblemente opera en la multitud de venezolanos de discutible trascendencia que comienzan a opacar los grandes títulos iniciales de Ayacucho, también registra manifestaciones más escabrosas. Una, relativamente sesgada, es la que se desliza en la carta a Darcy Ribeiro del 15 de octubre de 1976 respecto de la inconveniencia de publicar en lo inmediato la gran obra del brasileño, Las Américas y la civilización: "He preferido replantear el asunto a comienzos del año próximo, cuando ya hayan salido veinte títulos y comience a ser una colección académica muy variada de posiciones ideológicas" (RAMA, 15 de octubre de 1976).

Otra evidencia censora, mucho más incisiva, es la que le transmite a Cornejo Polar en la misiva del 2 de junio de 1977, en la cual condena la actitud del peruano Luis Alberto Sánchez y la cruzada anticomunista en la que se embanderó:

la Comisión de la Biblioteca ha tenido que defender con aspereza su derecho a la autonomía técnica en el caso de Pablo Neruda que, gracias a la insidiosa intervención de tu compatriota Luis Alberto Sánchez ante sus amigos del gobierno venezolano, motivó una reclamación de la Presidencia. Defendimos la inclusión de Neruda y nuestro derecho a actuar sin presiones, cosa que seguimos haciendo ahora que Guillermo Sucre se ha plegado a esa campaña antikomunista y nos ha hecho una denuncia en la revista de Paz, Vuelta 4 (RAMA, 2 de junio de 1977).

El cierre de esa comunicación es pesimista respecto de la situación del propio Rama dentro de la BA: "Yo mismo no sé si seguiré mucho tiempo aquí visto cómo se anuncia la campaña electoral del partido de gobierno" (íbid.).

\section{Brasil, ese convidado incómodo}

La presencia de Brasil en una colección latinoamericanista como la BA siempre 
acarrea la condición inconfortable de una zona que se integra difícilmente al resto del continente y que, en el caso de la literatura, arrastra el agravante de emplear una lengua diferente al español cuyas variantes dialectales no perturban la unidad de los otros países, como sostenía Pedro Henríquez Ureña en La utopía de América (HENRÍQUEZ UREÑA, 2000). Es cierto que en el orden lingüístico es igualmente complicada la inserción del Caribe francés, pero en ese caso la opción consiste en reducir al mínimo tal presencia -el ejemplo lo provee Gobernadores del rocío de Jacques Roumain--, acaso confiando en que parte de esa integración era cumplida desde Casa de las Américas, motor cultural encendido y mantenido por la Revolución Cubana en el cual revistaba como intelectual clave el haitiano René Depestre. El Caribe inglés, cuya pertinencia podría discutirse en la Ayacucho en tanto no comporta una lengua latina -aunque por historia, tradición y cultura indudablemente debería sumarse; más aún si se tiene en cuenta que la colección publica al alemán Humboldt (aunque sus libros sobre América fueron redactados en francés) y al norteamericano Hudson--, quedó reducido a una serie de títulos desgranados por Rama en la carta a José Ramón Medina del $1^{\circ}$ de mayo de 1979, enviada desde la Universidad de Stanford (RAMA, 1 de mayo de 1979).

Rama procura resolver la representación de Brasil a partir del diálogo con algunos interlocutores privilegiados como el antropólogo Darcy Ribeiro, el crítico literario Antonio Candido y la estudiosa del arte Aracy Amaral. Los dos primeros contribuyen en los aspectos literarios y la tercera es convocada para una antología del modernismo y para sugerir (y obtener) obras que podrían ilustrar las portadas de los volúmenes de autores brasileños (RAMA, 20 de marzo de 1977). Si la restricción a este triunvirato ya marcaba un obstáculo evidente frente a la fluidez de vínculos con intelectuales de Hispanoamérica, un impedimento adicional es la negativa del gobierno dictatorial instalado en 1964 a autorizar la salida del país de Caio Prado Júnior, convocado para la reunión caraqueña en que se organiza la Biblioteca (RAMA, 2008).

La relación más estrecha de Rama con Brasil la garantizan Darcy y su esposa Berta, como certifica el intercambio epistolar iniciado tras la estadía de Ribeiro en Montevideo, exiliado a mediados de los años 60, y continuado hasta la muerte de Ángel. Las cartas que tramaron Rama y Darcy conservan la lengua propia de cada uno, en tanto las que cruzaron Ángel y Berta están en español (COELHO; ROCCA, 2015). Las de los hombres se expanden en tópicos que marcan la indecisión de los corresponsales sobre su propia situación. El destierro domina varios escritos, modulando y atemperando la perspectiva: una postal de Darcy de 1964 (cuyos destinatarios son Rama y su primera esposa, la poeta Ida Vitale) que estima la presencia de los amigos con "la seguridad de que en la oscuridad y en el silencio de esta noche se está generando el amanecer" (Íbid., pág. 61); la carta del 10 de diciembre de 1975 que desdramatiza la expatriación como "esta vida divertida" (Íbid., pág. 65); la convicción de Rama (el 15 de abril de 1981) de que regresar del exilio es volver a vivir, cuando comenta la felicidad de Darcy de haber retornado a Brasil (Íbid., pág. 99).

El tema se articula con la soberbia reiterada del antropólogo, quien se hace llamar 
Emperador por una fantasía infantil, se ufana de las múltiples ofertas que recibe para ser traducido y apura la edición de su libro Las Américas y la civilización en Ayacucho, desatendiendo las precauciones de Rama sobre la ocasión política de incluir el título y azuzándolo con una vislumbre de trascendencia en carta del 14 de febrero de 1977: “¿No te aterra el juicio de la posteridad sobre la claudicación del supereditor, glorioso y sesquicentenario, que se olvidó de editar a Darcy?" (Íbid., pág. 85). Como las revelaciones de la intimidad suelen ofrecer tanto un incentivo a la investigación como un desaliento en torno a las conductas, la correspondencia revela que, mientras Darcy es un ferviente impulsor de la colección dirigida por su amigo y un enfático promotor de los autores brasileños dentro de ella, también opera como un sujeto calculador que trata de conseguir algún beneficio, se demora en la entrega del prólogo a Casa grande y senzala de Gilberto Freyre, contrata como manager a Carmen Balcells (sobre cuyas demandas excesivas se pronuncia Berta en carta a Rama del 9 de octubre de 1976) (íbid., pág. 139) y sostiene una cuenta bancaria en Nueva York que no parece afín a la situación económica que describe.

La intimidad de Rama que se puede indagar en el intercambio con los Ribeiro había sido revelada en parte en el Diario 1974-1983, plagado de versiones deprimentes de ciertos hechos y episodios relatados con menos amargura en las cartas, como el registro de la reunión de especialistas en el momento de planificar la Biblbioteca o la desazón que lo embarga cuando se desempeña como profesor en la Universidad de Stanford, en un medio ajeno con el que no siente afinidad alguna (RAMA, 2008). Lo que agrega la correspondencia con los antropólogos amigos ya no se desenvuelve en el marco de la sensibilidad que desarrolla el Diario sino que atañe al plan de obras brasileñas para Ayacucho, con algunas modificaciones en cuanto a la versión final y una serie de vaivenes en torno a la portada escogida para el libro de Freyre que ocupa casi la totalidad de los mensajes intercambiados con Berta en la segunda mitad de 1976 (COELHO; ROCCA, 2015).

Las misivas entre Rama y Berta desbordan afectuosidad. En ellas los corresponsales se reconocen también correspondientes: mientras Ángel difunde a los autores brasileños en Ayacucho, Berta publica libros latinoamericanos en la editora Paz e Terra y, así como reclama "mi medalla de reconocimiento por parte de la cultura brasileña" (4 de octubre de 1976) (íbid., pág. 135), Berta aspira asimismo a la suya, sin dejar de preguntarse "quién nos va a dar esa medalla" (23 de octubre de 1976) (íbid., pág. 149).

Aunque se empeñan en dar noticias constantes de Darcy, como si tal mediación fuera irrenunciable, las cartas de Berta proveen bibliografía inestimable -el caso de Antes el mundo no existía, mitología de los indios desâna que Ángel incorpora en 1982 a Transculturación narrativa en América Latina (RAMA, 2007)-- y recomiendan autores nuevos, como Rubem Fonseca. Si bien soportan hiatos extensos (entre diciembre de 1977 y mayo de 1982 hay una interrupción inexplicada, de difícil atribución), prefieren la continuidad frente a la corresponsalía salteada de Darcy. La última de ellas, el 19 de julio de 1983, se cierra con una frase promisoria de Berta: "Hasta cualquier día” (COLEHO; ROCCA, pág. 188). Rama y su esposa Marta Traba mueren el 27 de noviembre de ese año en un accidente aéreo, 
arrebatando a Darcy la fantasía retrospectivamente premonitoria del 25 de febrero de 1976: "te preciso bien vivo y muy lúcido hasta octubre de 1983, que es cuando voy a morir" (Íbid., pág. 68).

La carta de Darcy del 7 de julio de 1976 contiene las sugerencias de las obras brasileñas que la BA debería publicar y las recomendaciones de anotadores y prologuistas de cada una de ellas, listado que se transcribe a continuación, distinguiendo entre narrativa (y ocasionalmente poesía) y ensayística, e indicando entre corchetes los cambios que sufrió esta nómina en las ediciones efectivas de la colección:

- Manuel A. de Almeida (Memórias, etc.) - Francisco de Assis Barbosa [finalmente, Antonio Candido, cuyo artículo "Dialética da malandragem" fue reproducido como prólogo]

- Machado de Assis (2 novelas) - Roberto Schwarz [finalmente, Cuentos, a cargo de Alfredo Bosi y Quincas Borba, a cargo de Schwarz]

- Lima Barreto (2 novelas) - Carlos Nelson Coutinho? [finalmente, F. de Assis Barbosa]

- Oswald de Andrade (Miramar) - Haroldo de Campos [finalmente Obra escogida]

- Mário de Andrade (Macunaíma) - Gilda de Melo e Souza [finalmente Obra escogida]

- Graciliano Ramos (3 novelas) - João Luis M. Lafetá - NO APARECIÓ

- Guimarães Rosa (Grande Sertão) - Benedito Nunes - NO APARECIÓ

- Mário da Silva Brito (História do modernismo e Antologia poética) - NO APARECIÓ

- Carlos Drummond - Obra poética (Maria Luíza Ramos) - NO APARECIÓ

- Antologia do conto contemporâneo - Alfredo Bosi - NO APARECIÓ

Ensayística:

- Sílvio Romero (Leitura) - Antonio Candido [finalmente, Ensayos literarios]

- Euclides da Cunha (Os Sertões) - Walnice Nogueira Galvão

- Capistrano de Abreu (Capítulos, etc.) - José Honório Rodrigues

- Sergio Buarque de Holanda (Visão do paraiso) - Maria Odila da Silva Dias [finalmente, Francisco de Assis Barbosa]

- Gilberto Freyre (Casa grande) - Darcy Ribeiro

- Caio Prado Júnior (Formação) - Francisco Iglesias - NO APARECIÓ

- Celso Furtado (Formação) - NO APARECIÓ

- Darcy Ribeiro (As Américas) - Volumen tardío, el 180 (1992), prologado por María Elena Rodríguez Ozán y preparado por Mercio Pereira Gomes

- Florestan Fernandes (Ensaios sociopolíticos) - Fernando Henrique [Cardoso] - NO APARECIÓ

- Joaquim Felício dos Santos (Memórias, etc.) - Alexandre E. P. da Cunha - NO APARECIÓ

A este plan inicial se agregaron en la publicación definitiva dos volúmenes: uno de 
Antonio Candido (Crítica radical), preparado por Márgara Rusotto, y otro de Joaquim Nabuco (Un estadista del Imperio y Otros textos), organizado por Francisco Iglesias.

El listado de Darcy parece haber sido aceptado por Rama en líneas generales, como lo evidencia la correspondencia que el director literario de la Biblioteca mantiene con Aracy Amaral, cuyo libro Artes Plásticas na Semana de 22, lanzado en 1970 y que para esa altura iba por la tercera edición, la convertía en referente insoslayable para consultar las obras más adecuadas a los fines de ilustrar las portadas de los textos seleccionados. En carta del 20 de marzo de 1977 Rama le solicita "al menos dos diapositivas de seis por seis para cada uno de los títulos que te enumero, y que están puestos en el orden de aparición" (RAMA, 20 de marzo de 1977). La nómina es bastante semejante a la propuesta por Darcy, aunque la organización varía y hay más precisiones en torno a las obras específicas en cada caso (de Machado se lanzará Quincas Borba, y de Lima Barreto Recordações do Escrivão Isaías Caminha y Triste fim de Policarpo Quaresma). El remate lo constituye la Antología del modernismo que Rama ya le había encargado a Aracy y que se convertirá en Arte y arquitectura del modernismo brasileño (1917-1930), que constituye el volumen 47 de la BA.

Si bien el nombre Biblioteca Ayacucho se emplea para identificar a la Colección Clásica que constituye la base del emprendimiento y la creación efectiva de Rama, en los años siguientes a la fundación se fueron desprendiendo otras series para cubrir aspectos que la voluntad más canónica de esa nómina y la estructura de los volúmenes no permitían incorporar en dicho catálogo. Así se fueron sucediendo agrupaciones de libros bajo la designación de Paralelos, Futuro, Prólogos, Claves Políticas de América, Claves de América, La Expresión Americana, Documentos y el Diccionario Enciclopédico de las Letras de América Latina (DELAL), como coronación del repertorio reunido por Ayacucho. Pero no es la voluntad de este artículo indagar tales colecciones, ya ajenas a la órbita de Rama y al proyecto original, sino subrayar una particularidad de la Biblioteca que contribuye a marcar su carácter peculiar: la articulación entre los textos ofrecidos y las portadas de las lujosas ediciones que componen la serie. A esa dialéctica entre lo verbal y visual se entrega el último parágrafo del artículo.

\section{Texto, paratexto y contexto}

En el plano de las imágenes existe una coincidencia evidente entre la Biblioteca Ayacucho y la Colección Archivos, lo que confirma que Ayacucho fue una guía a la cual no pudo sustraerse el proyecto filológico: tanto uno como outro conjunto acuden habitualmente a una obra artística cuyo autor es de la misma nacionalidad que el escritor al que acompaña. No es condición excluyente ni se trata de una regla inviolable, pero suele ocurrir. Cuando no acontece, el efecto puede ser más impactante que en los otros casos. Un ejemplo pontual lo comprueba: El dolor paraguayo de Rafael Barrett lleva en la portada una reproducción de Sin pan y sin trabajo, obra canónica de Ernesto de la Cárcova. Barrett era un 
anarquista español que se propuso denunciar el sistema de explotación en los yerbales; de la Cárcova era un pintor académico argentino -autor, entre otros, del emblema de la Universidad de Buenos Aires, de corte netamente neoclásico-- que hizo una pausa en el retrato convencional y la pintura de caballete para registrar el drama social del desempleo y el hambre. El dolor paraguayo, asistido por dos figuras tan dispares que tienen un momento de inesperada coincidencia, es un milagro creativo en tanto ejemplar de la Biblioteca y reclama menos un lector informado de semejantes pormenores que un receptor sensible a esa filigrana.

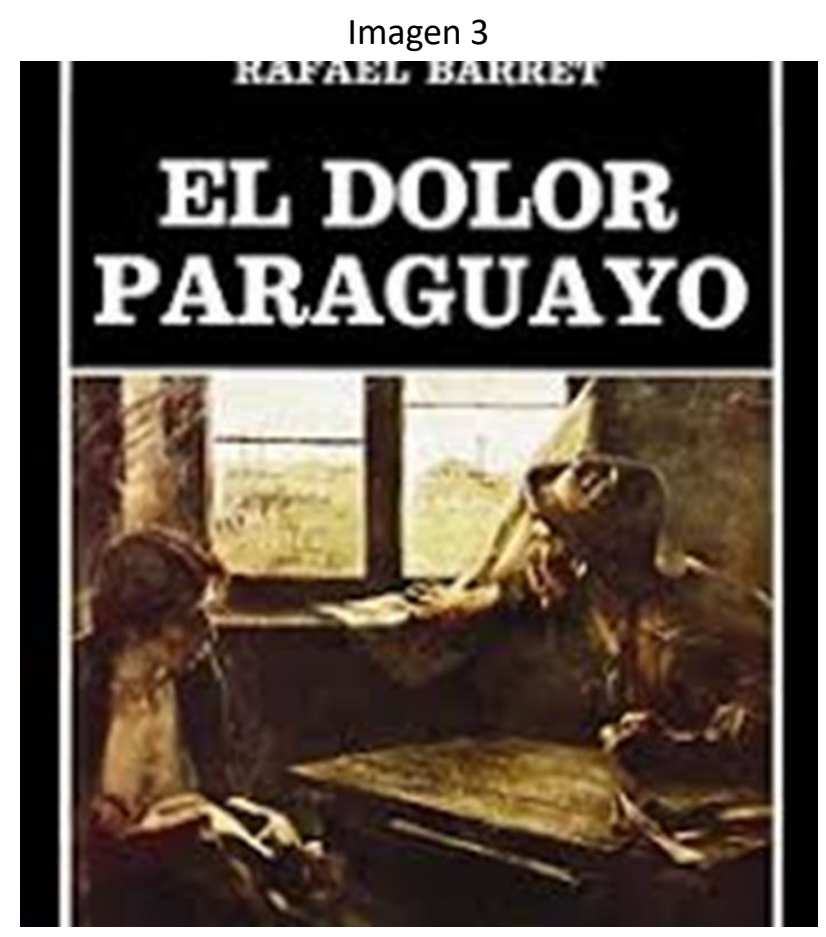

La mirada a vuelo de pájaro sobre el conjunto de las portadas confirma la aptitud para la convergencia, aunque generalmente más apaciguada que en el caso referido. La Nueva Corónica de Guamán Poma aparece antecedida por los dibujos que el autor diseñó a fin de exponer la particularidad de la sociedad andina como transición del Tawantisuyo a la imposición hispánica; Los sertones exhibe a un cangaceiro, acaso la figura más próxima (si bien folklorizada) a los yagunzos reprimidos en la masacre de Canudos; Cecilia Valdés lleva en la portada una pareja de esclavos que bien podría ser una muestra de ese producto típico de la Colonia americana que fue la pintura de castas en los grandes virreinatos; la obra de Huidobro se presenta a través de un retrato dibujado por Hans Arp. Las máscaras indígenas, los tejidos, las pinturas abstractas, los paisajes no son multitud en la colección, pero revisten una función armónica innegable: artesanías y textiles acompañan las antologías de poesía precolombina, Emilio Pettoruti y Alejandro Xul Solar ilustran a los vanguardistas.

Cuando autor y pintor coinciden en su nacionalidad, ocurren fenómenos como el de El niño de Vallecas de Fernando Botero en la fachada del libro que incluye dos novelas de 
Gabriel García Márquez. El cuadro renuncia momentáneamente a la obesidad malsana de los personajes de Botero y suspende el colorismo habitual para optar por la familiaridad con los enanos y los contrahechos que fascinaban a Velázquez, en sucesión con la perversa Menina envejecida que forma pendant con este muchacho y con la Mona Lisa infantilizada con que el artista homenajea a los europeos, tras haber iniciado la práctica con su versión de la Camera degli Sposi de Andrea Mantegna. Botero tenía cierta tradición como ilustrador de textos colombianos: en 1958 había acompañado el cuento del mismo García Márquez "La siesta del martes", publicado en el diario El Tiempo de Bogotá (y luego incluido en Los funerales de la Mamá Grande, 1962), y en 1961 expuso dibujos realizados para El gran Burundú Burundá ha muerto de Jorge Zalamea, novela escrita y editada originalmente en Buenos Aires en 1952. No podía ser ajena a Rama esta actividad de Botero a la hora de elegir la tapa de El coronel no tiene quien le escriba y Cien años de soledad: en su opúsculo Los dictadores latinoamericanos abordaba la novela de Zalamea (RAMA, 1976), quien había sido el anterior suegro de su esposa Marta Traba; además, a través de la residencia de Marta en Colombia en los años 60, estaba familiarizado con el mundo artístico local del cual ella se había ocupado en sus estudios.

En cambio, convocado como portada de Pensamiento conservador, es el Botero más reconocible el que se impone: por la gordura, por la gama cromática, por el porte de la tela $E I$ cardenal, en lugar de la pintura de corte de Velázquez o de los retratos de Leonardo y de Mantegna se filtra un aire anticlerical en la figura, más próxima a las imágenes incisivas de las películas de Luis Buñuel que a las representaciones del Quattrocento. Los lentes no alcanzan a corregir el desvío visual que padece el religioso y trasuntan la mirada congestionada e irregular que introduce un juicio preliminar en torno al conservadurismo recogido en el volumen a cargo de José Luis y Luis Alberto Romero.

Los Romero son la excusa para pasar al momento argentino de la exposición. Proyecto y construcción de una nación de Tulio Halperin Donghi, causa de las observaciones ya consignadas, lleva en la portada un cuadro que corresponde al recorte final del período estabelecido (1846 a 1880), que es una de las telas apaisadas y minuciosas con que Cándido López documentó ese episodio inclemente de la historia sudamericana que es la Guerra del Paraguay o, como prefieren designarla en Brasil, Guerra de la Triple Alianza. La asociación de Argentina, Brasil y Uruguay para arremeter contra Paraguay y aniquilar la república dominada por Francisco Solano López, derivó en el choque más sangriento de las luchas continentales. El "proyecto y construcción" de la Argentina queda así coronado por la actuación de las tropas nacionales en una contienda feroz. Sin embargo, a fin de reducir la vehemencia en pos del equilibrio histórico del trabajo de Halperin Donghi, la pintura elegida no se detiene en la batalla de Curupaytí (que López desplegó tanto desde la perspectiva argentina como desde la brasileña con precisión de miniaturista, pese a que en ese momento una granada le destrozó el brazo derecho), ni opta por los fogonazos de la fusilería, sino que es una vista del campamento militar en Curuzú, en el momento previo a la toma de Curupaytí. El recorte de la imagen deja fuera de campo las banderas argentina y brasileña 
que flamean próximas a la tienda y destaca los barcos entre los cuales se perciben los palos derribados del acorazado Rio de Janeiro torpedeado por los paraguayos, a consecuencia de lo cual fueron despojados del campamento donde se asentó el vizconde de Porto Alegre.

De la batalla de Curupaytí participó el coronel Lucio Victorio Mansilla, de quien la Biblioteca incluye Una excursión a los indios ranqueles, iniciado como sucesión epistolar en 1870 para constituirse en libro en 1875. La edición de esta obra en el plan general introducía una variante antropológica en el tratamiento de la figura del indígena que contradecía el "proyecto y construcción" de la nación y mostraba una alternativa a la Conquista del Desierto encabezada por el general Julio Argentino Roca en 1879. Sin embargo, la imagen de portada desmiente la cordialidad de Mansilla con los ranqueles, ignora los brindis en medio de la pampa y descarta la fascinación del militar con el cacique Mariano Rosas para optar por una visión esquemática de la presencia aborigen en La vuelta del malón (1892) de Ángel Della Valle. Nuevamente, la selección de una parte del cuadro suspende el conjunto de la composición e incluso le resta vigor narrativo a la pintura. La tela de Della Valle destaca tanto la figura del indio que porta en su caballo a una cautiva blanca -adicionalmente, vestida del mismo color y con una palidez que contrasta con la piel oscura de los jinetes-- como la del sujeto desaforado que parece guiar con el emblema católico a sus secuaces cargados de orfebrería religiosa, la cual queda así sometida a la herejía indígena. La portada de Ranqueles parece más propicia para La cautiva de Echeverría o para La vuelta de Martín Fierro, y apuesta antes al impacto de la imagen que a la concordancia con el texto que acompaña.

Por el contrario, esta asimetría desaparece en las portadas de autores brasileños, acaso por la elección precisa operada por Aracy Amaral. Basten como muestra los volúmenes dedicados a Lima Barreto y a Oswald de Andrade. El primero es adelantado por Suburbio carioca de Emiliano Di Cavalcanti. No obstante, aunque el tema coincide con uno de los más transitados por el escritor -recientemente, en la monumental biografía que dedica a Lima Barreto, Lilia Moritz Schwarcz diseccionó la mirada limana sobre el suburbio, destacando el papel que las estaciones ferroviarias tuvieron en las crónicas del escritor, sobre todo a partir del correlato social que reviste cada una (SCHWARCZ, 2017)-- existen varios elementos discordantes. Por un lado, los colores vivos que contrastan con la grisalla que la mirada melancólica impone en los textos de Lima; por otro, la disonancia de Di Cavalcanti, figura del Modernismo plástico, para ajustarse a Lima Barreto, quien desestimó ese fenómeno estético adjudicándolo a las supersticiones paulistas y polemizando con la revista Klaxon. Sin embargo, Di Cavalcanti era un artista reconocido en los años 20 y una de las figuras indagadas por Aracy Amaral en Artes Plásticas na Semana de 22 (AMARAL, 2010).

La consonancia absoluta de Oswald y Tarsila do Amaral ya ha sido tan transitada que no amerita mayor justificación. Solo que en lugar del previsible Abaporu que acompañó la primera edición del Manifiesto Antropófago en 1928, la pintura escogida para introducir al volumen de Oswald es Antropofagia, presentada por Tarsila en la exposición que realizó en Rio de Janeiro en 1929 y reproducida en un artículo de la Revista de Antropofagia en su "segunda dentición". Como en el Abaporu, la figura humana es inarmónica, con 
extremidades gigantescas y una cabeza diminuta, rasgos que condensan el repudio a la lógica occidental que el Manifiesto proclamaba con la insolencia de los descastados. También, como en el cuadro previo, la naturaleza brasileña que se reconoce en las hojas de banano y el sol metaforizado en una rodaja de lima dan cuenta de un espacio tropical que rechaza las imposiciones externas (MICELI, 2003). A su vez, como en La negra, el cruce de piernas subraya un único seno gigante, ubérrimo.

Una opción similar impregna las tapas de La vorágine y de Nuestra América. La Amazonia cauchera en el caso de Rivera y el Caribe insular en el caso de Martí muestran las alternativas de dos comarcas. Con ese término distinguió Rama las regiones americanas que encontraban un reconocimiento interno que superaba las fronteras nacionales y en las que se desarrolló una cultura reacia a los cánones metropolitanos e inespecífica en términos estatales (RAMA, 1979). Por eso la Selva de ramas entrelazadas (1956) de Lasar Segall es una imagen apta para la Amazonia que se despliega en La vorágine y que no permite identificar dónde acaban los límites colombianos y en qué punto se superponen a los brasileños y a los peruanos, simplemente porque esa naturaleza pródiga y peligrosa no admite mojones ni tratados fronterizos. Igualmente inespecífico en términos nacionales era Lasar Segall, nacido en Lituania e incorporado a la cultura brasileña en la década de 1920, tras el matrimonio de su hermana con el industrial paulista Klabin, quien le abrió al pintor el acceso a la clase alta metropolitana que inmediatamente lo llenó de encargos (MICELI, 2012).

El libro de Martí lleva en la portada la Fête créole de Laurent Casimir, un artista haitiano que permite evitar la pintura académica cubana de la época martiana y esquivar, menos justificadamente, las obras del isleño Wifredo Lam, acaso por excesivamente intelectualizadas en función de la vanguardia europea en cuyo marco se formó, tal vez por las resonancias que otorga a la santería e introducen una dimensión irracional allí donde Martí instalaba un programa político. Lo significativo es que la obra de Casimir, con su colorido y sus personajes alongados en medio de la celebración -son los años iniciales de la Carifesta inaugurada en 1972, que nuclea la producción cultural regional-- vuelve a insertar a Martí en la comarca caribeña, sin quitarle la dimensión latinoamericana amplia sino potenciándola en esa suerte de Aleph nuestroamericano que es el mar interno del que han surgido los grandes utopistas continentales: el mismo Martí, Eugenio María de Hostos y Pedro Henríquez Ureña. Tampoco es menor la circunstancia de que intelectuales haitianos como René Depestre apoyaran a la Cuba revolucionaria y colaboraran en la dificultosa construcción de un socialismo con rostro humano que, para el momento de iniciar la Biblioteca Ayacucho, ya constituía una de las grandes decepciones de Rama en vez de la fulgurante utopía de América que había pretendido ser.

Otra Cuba, no la de la Revolución, es la que rescata la colección en los años 70, acaso no solamente por la distancia que Ángel había tomado respecto de la política isleña, sino también por la que el gobierno venezolano, responsable final de la Biblioteca, prefería mantener. Es así como aparece Eliseo Diego, figura del grupo Orígenes, aunque bastante tardíamente; poco antes había salido Tres tristes tigres, la novela vanguardista de Guillermo 
Cabrera Infante, cuya ruptura con la dirigencia revolucionaria venía desde que decidió abreviar inopinadamente el nombre del periódico que manejaba, Lunes de Revolución, a la pura denotación de Lunes. Cabrera Infante era, como subraya la anécdota, un provocador; Eliseo Diego, en cambio, era un poeta que confluía en el mismo grupo que José Rodríguez Feo, Gastón Baquero, Virgilio Piñera y Fina García Marruz, liderado por José Lezama Lima. El reino de la imagen es el volumen antológico que se le dedica a Lezama Lima, que incluye una de las obras más luminosas para comprender la cultura continental: La expresión americana. En esa serie de cinco ensayos, Lezama sostiene que América es la cuna del barroco, y si comienza el recorrido en los versos deslumbrantes de Sor Juana Inés de la Cruz y en los alambicados de Carlos de Sigüenza y Góngora, prosigue la indagación en la arquitectura colonial producida por el indio Kondori, quien provee los rasgos mestizos que identifican al barroco peruano, y por el Aleijadinho, quien inserta los elementos negroides en el barroco minero, bastante más tardío y sugestivamente diverso.

Sin embargo, no son esos artistas los que acuden en la imagen de tapa del volumen, sino René Portocarrero, sindicado de barroco del siglo XX, acaso por la seducción que el paisaje habanero ejerció en sus pinturas. La reedición de El reino de la imagen ya en los 2000 volvió a Portocarrero pero cambió la vista de La Habana por el Interior del cerro, desplazando la arquitectura de cúpulas y ventanas --en cuyos postigos y celosías se insinúan las historias mínimas que definen la "sabrosura" de los Tratados en La Habana lezamianos-- por la centralización humana rodeada de un mobiliario en el que las curvas y las columnas reponen el esplendor barroquista, no ya como arte de fachada sino como interior sobresaturado.

El barroco mexicano en el cual arraigaba su teoría Lezama Lima incluye una figura que se irá convirtiendo con el tiempo en ícono americano: la Virgen de Guadalupe. Sigüenza y Góngora desplegaba la mariofanía del Tepeyac en un extenso poema en octavas reales titulado Primavera Indiana. En 1794, cuando el manierismo de la aparición de 1531 era barrido por el racionalismo iluminista, Fray Servando Teresa de Mier pronunció un sermón en el cual la tradición guadalupana quedaba alterada. La Virgen ya no se aparecía en el Tepeyac ante el indio Juan Diego hasta imprimirse en su tilma, sino que reaparecía luego de que Santo Tomás la hubiera protegido de las manos de indios incrédulos y apóstatas. La versión quitaba la posibilidad de una revelación e insistía en mantener la doctrina en manos de la iglesia, lo que implicaba un trastorno político. El Ideario político del dominico, insertado en la Biblioteca Ayacucho, implantó en consecuencia a la Virgen de Guadalupe en la tapa. Pero, por tratarse de una reversión, la imagen misma aparece invertida y se la priva de los aspectos narrativos que suelen aparecer en los cuadros. En torno a la Virgen, en las esquinas de las representaciones, en las pinturas de Juan Correa -si bien no en las de Miguel Cabrera, también retratista de Sor Juana-- constan las cuatro mariofanías ante Juan Diego.

En la historia de la cultura americana que traza Lezama Lima, Fray Servando es el enlace entre el barroco de Sor Juana y el criollismo de Martí pero, obnubilado por la recuperación del barroco, suspende allí el recorrido y suprime cualquier reconocimiento al modernismo hispanoamericano como momento de autonomía literaria. El autor clave para 
producir semejante fenómeno fue Rubén Darío, cuya estética no revestía afinidad alguna con los intereses lezamianos ni se imbricaba con la naturalidad que el cubano proponía dentro de la serie histórica arbitraria. Pero Darío no podía estar ausente del plan de Ayacucho, menos aún con la relevancia que Rama no solamente le atribuía sino que voluntariamente le concedía en sus primeros trabajos sobre el tema, que iría matizando y morigerando en lo sucesivo. Y si el barroco devenía en América "arte de la contraconquista" en la fórmula de Lezama, era recalcando la condición religiosa que se le adosaba en una Europa en la cual se lo consideraba "arte de la Contrarreforma" (WEISBACH, 1944), y que definía tanto la viabilidad de las imágenes que los jesuitas empleaban en la evangelización como los contornos de la Guadalupe. El modernismo, por su parte, vulneraba toda esa figuración ortodoxa y no vacilaba en recurrir a pintores decadentes y "malditos" que convertían la religión y sus avatares en objetos de escarnio, vituperando la santidad y la virginidad en mujeres fatales que arrastraban al mal haciendo gala de sus pompas y sus obras. Así, la fachada del libro de Rubén Darío corresponde al mexicano Roberto Montenegro quien, además de colaborar con Darío en la revista Mundial, participaba a comienzos del siglo XX de una estética aprendida menos en los pintores franceses y belgas que en los refinamientos laterales del español Hermenegildo Anglada Camarasa. Como la perversa Eulalia que brilla en el baile de máscaras de "Era un aire suave", la ambigua Dama del antifaz de Montenegro espía desde su escondite parcial en un ámbito azulado que enturbia cualquier imagen.

Una expansión más en torno a las postulaciones literario-plásticas de Lezama Lima, quien cuando aborda el momento criollista recupera tanto la escritura martiana como los grabados de José Guadalupe Posada. De esa serie de esqueletos que cantan corridos, toman tequila -aun a riesgo de que el líquido se les escurra en el vacío abdominal--, lanzan disparos al aire e inevitablemente portan el sombrero de ala gigantesca, subsisten las "calacas" como arte kitsch de las ferias mexicanas. Son las calaveras que, si en el Día de Muertos se moldean con azúcar, para el consumo artesanal están hechas de cerámica y se les aplica un despliegue multicolor. La celebración mortuoria tiene su epicentro en la Catrina, la Calavera Garbancera con sombrero de plumas y moños que la engalanan. Sin afán abarcativo, sin ostentaciones y libre de tales afeites -al contrario, con una prosa en cuya sequedad se imprime el paisaje de Jalisco y en cuya precisión se advierte la lectura sostenida de autores escandinavos de comienzos del siglo XX, como Knut Hamsun y Selma Lagerlöf-- se erige la obra de Juan Rulfo, que consta de una novela breve y un libro de cuentos. En el mundo de muertos que diseña esta narrativa, la Catrina es un espectro que ronda, sin la gracia del retrato ni la conjura del temor a la que apelaba Posada, sino con la mera resignación de quien se adentra en el infierno de la tierra caliente en busca del padre, de las antiguas posesiones, del honor, de la fe: todos perdidos. 


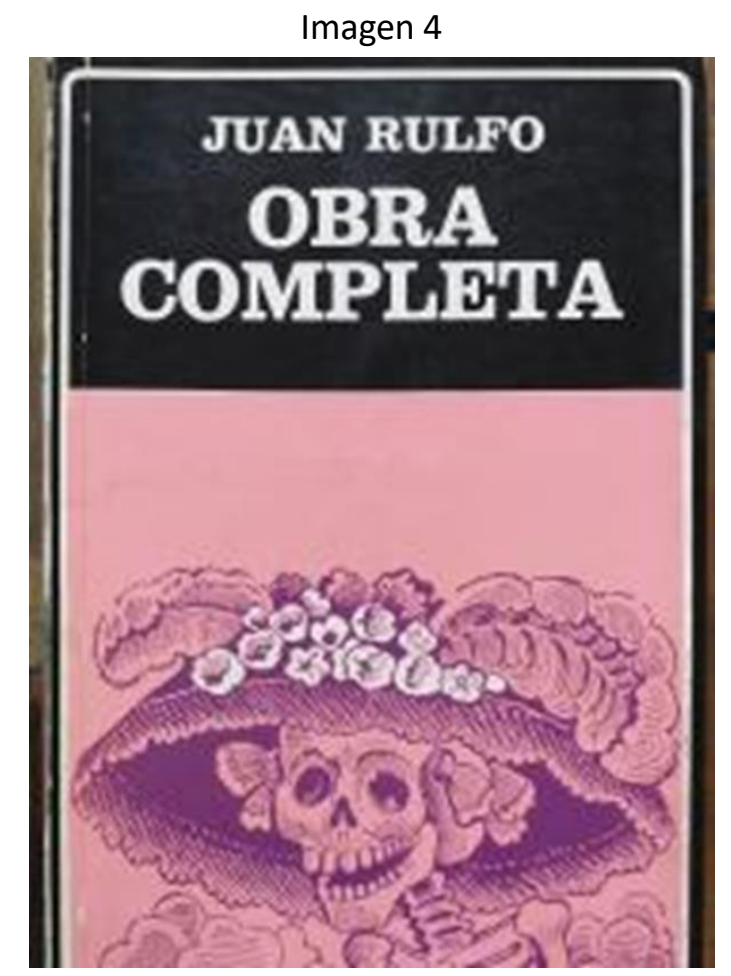

Coherente con el trío inicial de títulos de la colección en el cual el ensayo certificaba su aptitud para la definición continental con el Ariel de Rodó, los grandes ensayos serán convidados permanentes en el plan general. Contrapunteo cubano del tabaco y el azúcar de Fernando Ortiz instala un enfoque antropológico sobre la alternancia de la economía de Cuba entre dos productos que definen sistemas económicos disimétricos: un cultivo que favorece la esclavitud con el sujeto atado a la tierra en un régimen feudal y un cultivo anual que reclama un trabajador libre, contratado exclusivamente para la ocasión, en el protocapitalismo agrario. La imagen de portada es una litografía cubana del siglo XIX que parece inspirada en los cromos madrileños que ya había rescatado Julián del Casal en su poesía finisecular. Una figura neoclásica sobre el lado derecho, una plantación de tabaco sobre el izquierdo y, en el centro, un pretencioso escudo de armas, componen la heráldica comercial del producto. El libro de Ortiz es relevante para Ayacucho y para Rama: es allí donde encuentra el término "transculturación" que elevará a categoría teórica en la profusa indagación cumplida en Transculturación narrativa en América Latina (RAMA, 1982).

Entre la antropología y la sociología, aunque con una prosa decididamente literaria, se balancea Casa grande y senzala, el libro mayor de Gilberto Freyre. Aunque pretende ser representativo de Brasil, en verdad se concentra en la cultura del Nordeste, donde los señores ocupan la casa grande y los esclavos habitan la senzala contigua, proveyendo a los patrones de todo elemento y dotándolos de una cultura transportada desde África: canciones de cuna, comidas, dulces, bailes, iniciación sexual; no hay servicio que puedan escamotear. La exaltación casi amorosa del negro, al que se mantiene en un cautiverio escandalosamente justificado en el paternalismo y en que las condiciones de vida en una 
fábrica industrial del siglo XX son peores, es la contrapartida de la degradación del indígena y la denuncia de la molicie del blanco, quien se acostumbró a esa servidumbre absoluta y se volvió inútil. Peor aún: se entregó a especulaciones intelectuales, cuyo sedentarismo propició el daño físico terrible de las hemorroides. Las alternativas de la edición de este título en Ayacucho, como se consignó, constan en la correspondencia de los años 1975 a 1977 entre Rama y los Ribeiro por la cual se sabe que fue Berta quien procuró la imagen de tapa, que es un fragmento del mural de Cândido Portinari para el Ministerio de Educación en Rio de Janeiro, en el cual un negro se dobla bajo el peso de un conjunto de cañas que debe transportar, seguramente bajo la vigilancia sin indulgencia de un capataz feroz.

A esos ensayos que procuran explicar la realidad americana los contrarrestan, dentro de la misma colección, los textos entregados a sostener la ilusión de un continente. Para clausurar este itinerario caprichoso escojo dos fantasías memorables. Una, la de Sergio Buarque de Holanda, quien procura reconstruir la imaginación fascinada de los conquistadores portugueses que alucinaron un paraíso en las tierras donde se halló el Palo Brasil. "Motivos edénicos", sostiene el subtítulo de Visäo do Paraiso; en verdad, expectativas descontroladas que apuntaron a sustituir el afán de enriquecimiento con una vislumbre paradisíaca allí donde los beneficios materiales quedaban opacados por la naturaleza opima y el colorido espectacular. Las descripciones inconcebibles que acumula el análisis de Sergio vienen antecedidas por La flora y la fauna de Eldorado, como se titula el grabado que Theodor de Bry hizo para el libro de Walter Raleigh. De Bry nunca estuvo en América, pero siguió los dibujos y las indicaciones de quienes sí habían viajado y llegó a ilustrar la traducción inglesa (y luego la alemana y la latina) de la Brevísima historia de la destrucción de las Indias del padre Bartolomé de Las Casas. La flora y fauna de esta portada son tan fantásticas como Eldorado: en el centro del recorte hay un cuerpo zoológico con una cabeza humana; a la izquierda, una "símil loba" según indica el latinismo; a la derecha, el término "armadillo" no encontró equivalente para ser vertido a la lengua de las taxonomías europeas.

Final: La utopia de América es el empeño luminoso de Pedro Henríquez Ureña. Se trata de una utopía intelectual, la que incentivó la creación de la Biblioteca Americana y la que recupera Rama en el trazado de Biblioteca Ayacucho. Es la utopía de la educación popular, de las élites ilustradas, de la "raza cósmica" en la que se reunían todas las culturas según la visión prodigiosa de José Vasconcelos. Precisamente el plan educativo de Vasconcelos es el que retorna en el fragmento del mural de Diego Rivera que ocupa la portada. Fue Vasconcelos, como secretario de Educación de México (1921-1924), quien elevó el muralismo a política de Estado y a arte oficial. La ruptura irreversible entre Henríquez Ureña y él significó uno de los fracasos del utopismo; el exilio argentino de don Pedro, donde recibió desprecio y no encontró las condiciones intelectuales y afectivas que había hallado en México, fue otra de las derrotas de semejante empecinamiento. En cambio, el exilio venezolano de Rama, con todo lo que implica de tragedia personal, de desarraigo, de desolación, fue la circunstancia de creación del repertorio magnífico de Nuestra América, cuyo nombre emblemático y cuyo impulso expansivo justifican esta memoria entusiasta. 


\section{Referências}

AMARAL, A. Artes Plásticas na Semana de 22. São Paulo: Editora 34, 2010.

BELLO, A. Repertorio Americano. Caracas, Presidencia de la República, 1973.

COELHO, H. R.; ROCCA, P. Diálogos latino-americanos. Correspondência entre Ángel Rama, Berta e Darcy Ribeiro. São Paulo: Global, 2015.

HENRÍQUEZ UREÑA, C. Biblioteca Americana. México: Fondo de Cultura Económica, 1946.

HENRÍQUEZ UREÑA, P. Ensayos. Buenos Aires: Archivos, 2000. Edición de José Luis Abellán y Ana María Barrenechea.

HENRÍQUEZ UREÑA, P. Las corrientes literarias en la América hispânica. México: Fondo de Cultura Económica, 1949.

MICELI, S. Ensayos porteños. Bernal: Universidad de Quilmes, 2012.

MICELI, S. Nacional estrangeiro: história social e cultural do modernismo artístico em São Paulo. São Paulo: Companhia das Letras, 2003.

RAMA, A. Aportación original de una comarca del Tercer Mundo: Latinoamérica. México: Cuadernos de Cultura Latinoamericana 73, 1979.

RAMA, A. Diario 1974-1983. Buenos Aires: El Andariego, 2008.

RAMA, A. Los dictadores latinoamericanos. México: Fondo de Cultura Económica, 1976.

RAMA, A. Transculturación narrativa en América Latina. Buenos Aires: El Andariego, 2007

RODÓ, J. E. Ariel. Caracas: Biblioteca Ayacucho, 1976.

SCHWARCZ, L.M. Lima Barreto. Triste visionário. São Paulo: Companhia das Letras, 2017.

SEGNINI, Y. La Editorial América de Rufino Blanco Fombona. Madrid 1915-1933. Madrid: Libris, 2000.

VIÑAS, D. "Prólogo" a Obras escogidas de Armando Discépolo. Buenos Aires: Jorge Álvarez, 1969.

VIÑAS, D. “Prólogo" a Teatro rio-platense. Caracas: Biblioteca Ayacucho, 1978.

VIÑAS, D. De Sarmiento a Cortázar. Buenos Aires: Siglo Veinte, 1974.

WEISBACH, W. El Barroco, arte de la Contrarreforma. Madrid: Espasa-Calpe, 1942.

Correspondencia (Cartas remitidas por Ángel Rama)

Carta a Leopoldo Zea, 21 de agosto de 1975.

Carta a Sergio Ramírez, 3 de diciembre de 1975.

Carta a Leopoldo Zea, 16 de diciembre de 1975.

Carta a Darcy Ribeiro, 12 de marzo de 1976.

Carta a Mario Vargas Llosa, 22 de marzo de 1976. 
Carta a José Pedro Díaz, 31 de marzo de 1976.

Carta a José Pedro Díaz, 11 de junio de 1976.

Carta a Tulio Halperin Donghi, 6 de julio de 1976.

Carta a Aracy Amaral, 20 de marzo de 1977.

Carta a Sergio Ramírez, 18 de mayo de 1977.

Carta a Antonio Cornejo Polar, 2 de junio de 1977.

Carta a Tulio Halperin Donghi, 24 de noviembre de 1977.

Carta a Idea Vilariño, 14 de abril de 1978.

Carta a Tulio Halperin Donghi, 24 de agosto de 1978.

Carta a Antonio Cornejo Polar, 2 de octubre de 1978.

Carta a José Ramón Medina, 1 de mayo de 1979.

Recebido em: 09/08/2019.

Aceito em: 28/11/2019. 